University of Nebraska - Lincoln

DigitalCommons@University of Nebraska - Lincoln

6-1-1998

\title{
Phase formation and magnetic properties of Co-rare earth magnetic films
}

Yi Liu

University of Nebraska-Lincoln, yliu@unl.edu

Richard A. Thomas

University of Nebraska - Lincoln

S.S. Malhotra

University of Nebraska - Lincoln

Z.S. Shan

University of Nebraska - Lincoln

Sy_Hwang Liou

University of Nebraska-Lincoln, sliou@unl.edu

See next page for additional authors

Follow this and additional works at: https://digitalcommons.unl.edu/physicsliou

Part of the Physics Commons

Liu, Yi; Thomas, Richard A.; Malhotra, S.S.; Shan, Z.S.; Liou, Sy_Hwang; and Sellmyer, David J., "Phase formation and magnetic properties of Co-rare earth magnetic films" (1998). Si-Hwang Liou Publications. 69.

https://digitalcommons.unl.edu/physicsliou/69

This Article is brought to you for free and open access by the Research Papers in Physics and Astronomy at DigitalCommons@University of Nebraska - Lincoln. It has been accepted for inclusion in Si-Hwang Liou Publications by an authorized administrator of DigitalCommons@University of Nebraska - Lincoln. 


\section{Authors}

Yi Liu, Richard A. Thomas, S.S. Malhotra, Z.S. Shan, Sy_Hwang Liou, and David J. Sellmyer 


\title{
Phase formation and magnetic properties of Co-rare earth magnetic films
}

\author{
Y. Liu \\ Center for Materials Research and Analysis, and Department of Mechanical Engineering, \\ University of Nebraska, Lincoln, Nebraska 68588-0656
}

Richard A. Thomas, S. S. Malhotra, Z. S. Shan, S. H. Liou, and D. J. Sellmyer

Center for Materials Research and Analysis, and Behlen Laboratory of Physics, University of Nebraska, Lincoln, Nebraska 68588-0111

\begin{abstract}
$\mathrm{Co}-\mathrm{Sm}$ and $\mathrm{Co}-\mathrm{Pr}$ films were deposited by dc magnetron sputtering. Transmission electron microscopy and magnetic measurement were used to study the microstructure and magnetic property relationship. The nanostructure of the as-deposited Co 19 at. \% Sm films consists of two phases: the amorphous phase and the crystallite phase. Upon annealing at $600{ }^{\circ} \mathrm{C}$, the $\mathrm{Co}_{5} \mathrm{Sm}$ phase with the $\mathrm{Cu}_{5} \mathrm{Ca}$ structure, having grain size of about $20 \mathrm{~nm}$, is obtained along with high coercivity (45 kOe). The as-deposited Co 22 at. \% Sm films also have nanostructure similar to the Co 19 at. \% films except the volume fraction of the crystallite is reduced. This is related to the concentration of $\mathrm{Sm}$ which promotes the formation of the amorphous phase. A new metastable phase $\mathrm{Co}_{3} \mathrm{Sm}$ is formed upon annealing of the Co 22 at. \% Sm film at $500{ }^{\circ} \mathrm{C}$. This phase has the $\mathrm{DO}_{19}$ structure in which the Sm atoms take ordered positions of a triangular pattern in the close-packed planes. A relatively high coercivity value of $29 \mathrm{kOe}$ was obtained from this phase. The as-deposited Co-Pr films show mainly an amorphous phase. Upon annealing at $500{ }^{\circ} \mathrm{C}$ for $20 \mathrm{~min}, \mathrm{Co}_{2} \mathrm{Pr}$ with the $\mathrm{Mg}_{2} \mathrm{Cu}$-type structure was identified in the $\mathrm{Co} 35$ at. \% Pr film. Two phases were identified in the Co 16 at. \% Pr films. Coercivities up to $3.1 \mathrm{kOe}$ were achieved in these films. (C) 1998 American Institute of Physics. [S0021-8979(98)30611-8]
\end{abstract}

\section{INTRODUCTION}

Hard and semihard Co rare earth films are of increasing interest for magneto-electronic and magnetic-recording applications. The $\mathrm{Co}-\mathrm{Sm}$ and $\mathrm{Co}-\mathrm{Pr}$ systems also have high $T c$ suitable for high temperature magnets. A number of articles on the $\mathrm{Co}-\mathrm{Sm}$ and $\mathrm{Co}-\mathrm{Pr}$ systems have been presented. ${ }^{1-5}$ The magnetic properties of materials can be divided into intrinsic properties and extrinsic properties. The intrinsic properties such as magnetization are related to the crystal structure of the magnetic phase while the extrinsic properties such as coercivity are affected by the microstructure. Development of new magnetic materials involves the search for new magnetic phases and the design of microstructure. In this article we report our detailed study on phase formation, microstructure, and magnetic properties relationship in films based on the Co-Sm system and Co-Pr system heat treated at different temperatures.

\section{EXPERIMENTAL PROCEDURE}

For the Co-Sm system, the films were deposited by dc magnetron sputtering. Two compositions near the $\mathrm{Co}_{5} \mathrm{Sm}$ and $\mathrm{Co}_{7} \mathrm{Sm}_{2}$ were selected. All films have a $\mathrm{Cr}$ underlayer of about $90 \mathrm{~nm}$ except the one with the composition of Co 19 at. \% Sm annealed at $600{ }^{\circ} \mathrm{C}$ which is deposited on a quartz substrate. All the films have a Cr cover layer of about $10 \mathrm{~nm}$. For the Co-Pr system multilayers of $\mathrm{Co}-\mathrm{Pr} / \mathrm{Co}$ films were deposited using a multiple-gun dc and rf sputtering chamber. The multilayer microstructure is designed to promote magnetic hard phase and soft phase coupling in order to gain maximum energy product. A $50 \mathrm{~nm}$ underlayer and a $10 \mathrm{~nm}$ cover layer of $\mathrm{Cr}$ were used for film seeding and protection. Plan-view transmission electron microscopy (TEM) samples were prepared by dimpling and ion milling process. TEM study was conducted using a JEOL 2010 transmission electron microscope.

\section{RESULTS AND DISCUSSION}

The deposition parameters, film thickness, coercivity, and phase identification results are summarized in Table I.

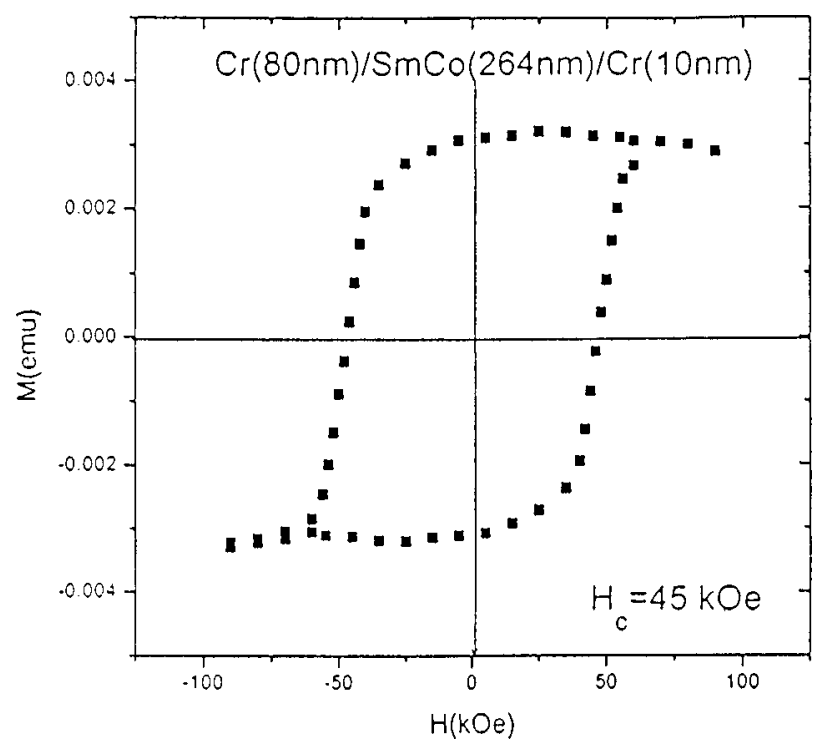

FIG. 1. Magnetization loop of the $\mathrm{Co}_{5} \mathrm{Sm}$ film annealed at $600{ }^{\circ} \mathrm{C}$. 
TABLE I. Composition, deposition condition, nanostructure, and magnetic properties relation in $\mathrm{Co}-\mathrm{Sm}$ and $\mathrm{Co}-\mathrm{Pr}$ films. C indicates crystallite phase and A amorphous phase. $\mathrm{Vc}$ is the volume fraction of the crystallite phase against the amorphous phase.

\begin{tabular}{lcccccc}
\hline \hline $\begin{array}{c}\text { Film com. } \\
\text { (at. \%) }\end{array}$ & $\begin{array}{c}\text { Ar pressure } \\
(\mathrm{mT} \text { Torr })\end{array}$ & $\begin{array}{c}\text { Film thickness } \\
(\mathrm{nm})\end{array}$ & Phases & $\begin{array}{c}\text { Vc } \\
(\%)\end{array}$ & $\begin{array}{c}\text { Grain size } \\
(\mathrm{nm})\end{array}$ & $\begin{array}{c}\text { Coercivity } \\
(\mathrm{kOe})\end{array}$ \\
\hline Co 19 at. $\% \mathrm{Sm}$ & 5 & 24 & $\mathrm{C}+\mathrm{A}$ & 91 & 5 & 0.61 \\
Co 19 at. $\% \mathrm{Sm}$ & 12 & 24 & $\mathrm{C}+\mathrm{A}$ & 65 & 5 & 2.58 \\
Co 19 at. $\% \mathrm{Sm}$ & 30 & 24 & $\mathrm{C}+\mathrm{A}$ & 54 & 5 & 0.92 \\
Co 19 at. $\% \mathrm{Sm}$ & & & & & & \\
Annealed at $600{ }^{\circ} \mathrm{C}$ & 20 & 360 & $\mathrm{Co}_{5} \mathrm{Sm}$ & 100 & 20 & 45 \\
& & & $\left(\mathrm{Cu}_{5} \mathrm{Ca}\right)$ & & & \\
Co 22 at. $\% \mathrm{Sm}$ & 5 & 30 & $\mathrm{C}+\mathrm{A}$ & 81 & 5 & 1.2 \\
Co 22 at. $\% \mathrm{Sm}$ & 17 & 30 & $\mathrm{C}+\mathrm{A}$ & 57 & 5 & 4.1 \\
Co 22 at. $\% \mathrm{Sm}$ & 30 & 30 & $\mathrm{C}+\mathrm{A}$ & 48 & 5 & 3.4 \\
Co 22 at. $\% \mathrm{Sm}$ & & & & & & \\
Annealed at $500{ }^{\circ} \mathrm{C}$ & & 394 & $\mathrm{DO}_{19}$ & 100 & 15 & 29 \\
\hline
\end{tabular}
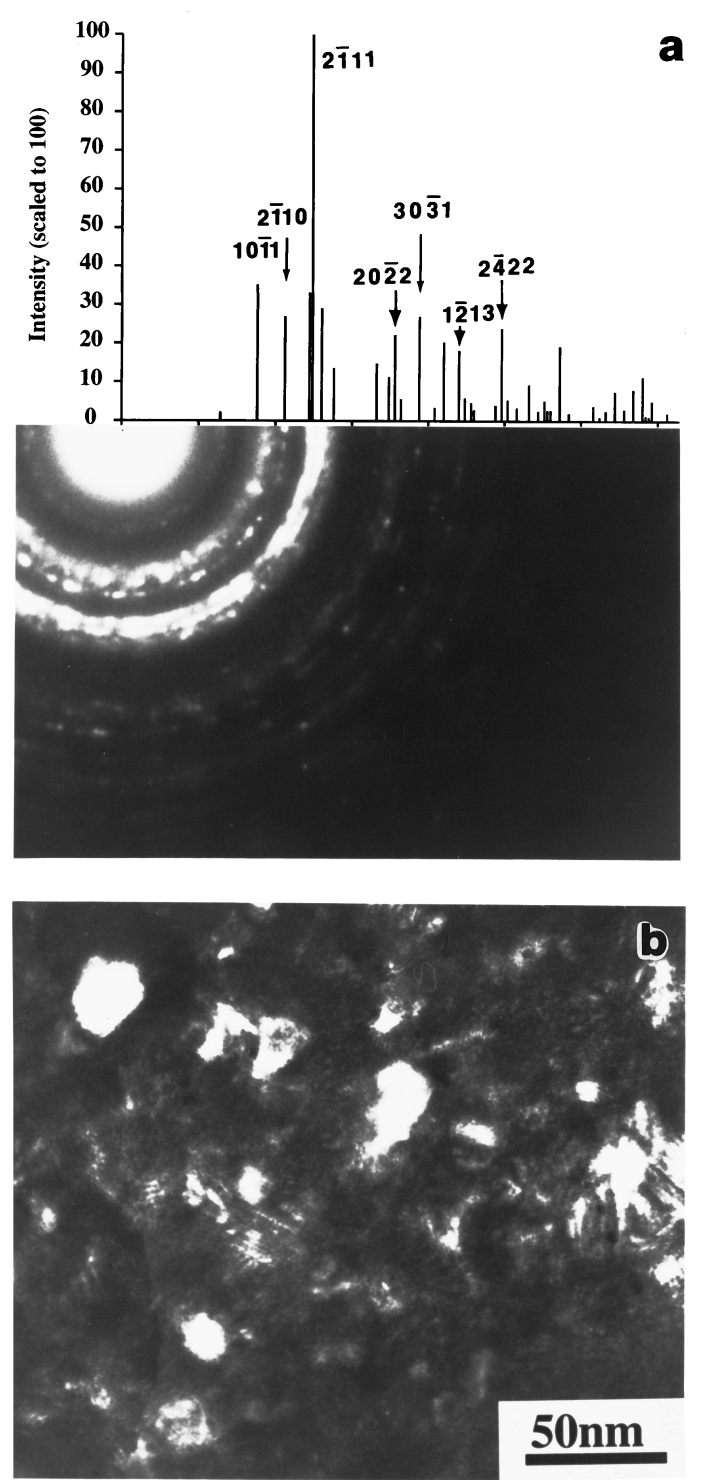

FIG. 2. (a) Comparison of SAD pattern and calculated intensity distribution for the film described in Fig. 1. (b) TEM image of the microstructure.
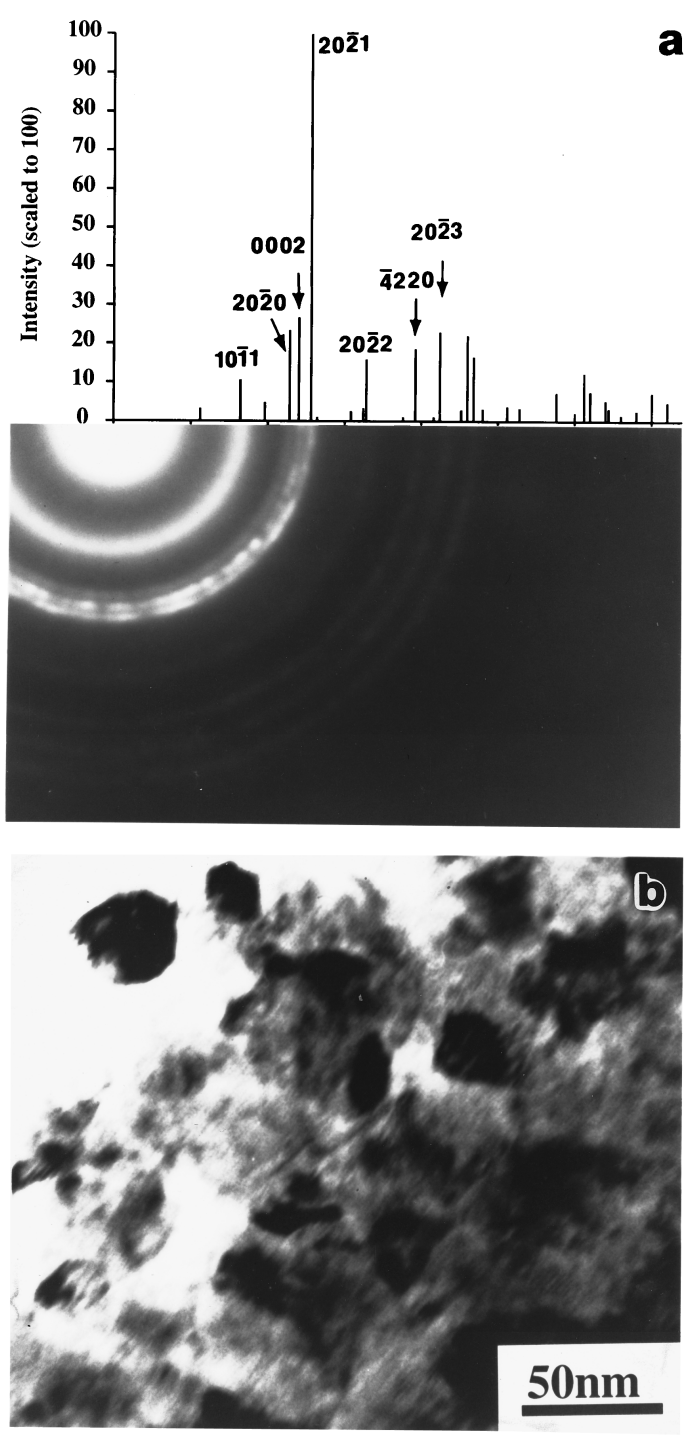

FIG. 3. (a) Comparison of SAD pattern and calculated intensity distribution for the Co 22 at. \% Sm film. (b) TEM image of the microstructure. 
The nanostructure of the as-deposited Co 19 at. \% Sm films has been studied in earlier work ${ }^{1}$ and is included here for comparison. Upon annealing at $600{ }^{\circ} \mathrm{C}$, the equilibrium phase $\mathrm{Co}_{5} \mathrm{Sm}$ with the $\mathrm{Cu}_{5} \mathrm{Ca}$ structure is obtained along with high coercivity. Figure 1 shows the magnetization loop. Coercivities up to $45 \mathrm{kOe}$ were achieved. Figure 2 shows the selected area diffraction (SAD) pattern and TEM micrograph. The diffraction shows perfect match with the calculated intensity. The grain size is about $20 \mathrm{~nm}$.

The Co 22 at. \% Sm films also have a nanostructure similar to the Co 19 at. \% films except the volume fraction of the crystalline against amorphous phase is reduced. This is related to the concentration of $\mathrm{Sm}$ which promotes the formation of the amorphous phase. Figure 3 shows the SAD pattern and the TEM image of the Co 22 at. \% Sm film annealed at $500{ }^{\circ} \mathrm{C}$. A new phase $\mathrm{Co}_{3} \mathrm{Sm}$ is formed as indicated by the matching of the TEM pattern and calculation. This phase has the $\mathrm{DO}_{19}$ structure in which the $\mathrm{Sm}$ atoms taking the ordering positions of a triangular pattern in the close-packed planes. The close-packed planes are stacked by the sequence of $\mathrm{ABAB}$ in the $c$ direction. A relatively high coercivity value of $29 \mathrm{kOe}$ was obtained from this phase.

The appearance of the $\mathrm{DO}_{19}$ structure is not a surprise but rather easy to comprehend. In the as-deposited $\mathrm{Co}-\mathrm{Sm}$ films, the structure of the crystallite is the close-packed structure with Sm atoms randomly distributed in the close-packed planes and short range packing order in the $c$ direction. Upon annealing, two things happened: one is that the Sm atoms within each close-packed plane form a triangular ordering pattern, and the second is that the packing in the $c$ direction takes the long range $\mathrm{ABAB}$ packing. The lattice parameters deduced from this phase are $a=0.256 \mathrm{~nm} c=0.419 \mathrm{~nm}$ compared to the lattice parameters of Co $a=0.2505 \mathrm{~nm}, 0.4065$ $\mathrm{nm}$. It is interesting to note that the lattice parameters between the $\mathrm{DO}_{19}$ phase and the Co phase are close to each other, suggesting a low energy state at the interphase. It is suggested that two-phase structure composed of $\mathrm{Co}$ and $\mathrm{DO}_{19}$ phase could be stable up to $500{ }^{\circ} \mathrm{C}$.
The as-deposited Co-Pr films show largely amorphous phase. Upon annealing at $500{ }^{\circ} \mathrm{C}$ for $20 \mathrm{~min}, \mathrm{Co}_{2} \mathrm{Pr}$ of the $\mathrm{Mg}_{2} \mathrm{Cu}$-type structure was identified in the Co 35 at. \% $\mathrm{Pr}$ film. Two phases were identified in the Co 16 at. \% Pr films. Coercivities up to $3.1 \mathrm{kOe}$ were achieved in these films.

\section{CONCLUSIONS}

Three metastable phases were found in the sputtered Co-Sm films: the amorphous phase, the close-packed hexagonal phase with different stacking mode in the asdeposited film, and the $\mathrm{DO}_{19}$ structure phase in the film annealed at $500{ }^{\circ} \mathrm{C}$.

Corresponding to the different phases and microstructure, the coercivities change from about 1-42 kOe. Maximum coercivity was achieved from the $\mathrm{Co}_{5} \mathrm{Sm}$ phase with the $\mathrm{Cu}_{5} \mathrm{Ca}$ structure. The new metastable phase of $\mathrm{DO}_{19}$ structure found in the Co 22 at. \% Sm film also showed relatively high coercivity of $29 \mathrm{kOe}$.

\section{ACKNOWLEDGMENTS}

The authors wish to thank Xueli Zhao for preparing the TEM samples. The TEM work was performed at the Central Facility for Electron Microscopy operated by CMRA. This research is sponsored by the U.S. Department of Energy, Grant No. DE-FG-02-86ER45262, National Science Foundation, Grant No. DMR-9623992, National Storage Industry Consortium, and CMRA. S. H. Liou is supported by the U.S. Army Research Office, Grant No. DAAG55-98-1-0014.

${ }^{1}$ Y. Liu, B. W. Robertson, Z. S. Shan, S. Malhotra, M. J. Yu, S. K. Renukunta, S. H. Liou, and D. J. Sellmyer, IEEE Trans. Magn. 6, 4035 (1994).

${ }^{2}$ Y. Liu, D. J. Sellmyer, B. W. Robertson, Z. S. Shan, and S. H. Liou, IEEE Trans. Magn. 31, 2740 (1995).

${ }^{3}$ S. S. Malhotra, Y. Liu, Z. S. Shan, S. H. Liou, D. C. Stanford, and D. J. Sellmyer, J. Magn. Magn. Mater. 161, 316 (1996).

${ }^{4}$ E. M. T. Velu and D. N. Lambeth, IEEE Trans. Magn. 28, 3249 (1992).

${ }^{5}$ K. Chen, H. Hegde, S. U. Jen, and F. J. Cadieu, J. Appl. Phys. 73, 5923 (1993) 